\title{
INFLUENCE OF COOLING CONDITIONS ON THE MACHINING PROCESS UNDER MQCL AND MQL CONDITIONS
}

\author{
Radoslaw W. Maruda, Stanislaw Legutko, Grzegorz, M. Krolczyk, Pero Raos
}

Original scientific paper

The paper presents the results of investigation of the influence of conditions of forming emulsion and oil mist on the chip shape and surface roughness of X10CrNi18-8 stainless steel during turning. In the tests, the following machining operations have been compared: dry machining, cooling by the MQCL (Minimal Quantity Cooling Lubricat) method, cooling by the MQL (Minimum Quantity Lubricat) method. The tests have been performed in two stages. In the first stage, the influence of the mass flow of the active medium on the chip shape and on the $R a$ and $R q$ roughness parameters of the machined surface have been determined. The purpose of stage two was to determine the influence of the MQL and MQCL method on the selected indices of the machining process as compared to dry machining as a function of variable cutting speed. It has been found that, under MQCL and MQL conditions, the area of formation of elemental chips and ones with the shape of short spirals is wider as compared to dry turning. With increased mass flow of emulsion and oil, tangled chip is formed. Cooling by the MQCL and MQL method results in reduction of the selected roughness parameter values by $2 \%$ to $42 \%$ as compared to dry machining.

Keywords: emulsion mist; chip shape; $M Q C L ; M Q L$; oil mist; surface roughness

Utjecaj uvjeta hlađenja na postupak obrade u uvjetima MQCL i MQL

Izvorni znanstveni članak U radu se predstavljaju rezultati istraživanja utjecaja uvjeta stvorenih djelovanjem emulzijske i uljne izmaglice na oblik strugotine i površinsku hrapavost nehrđajućeg čelika X10CrNi18-8 tijekom tokarenja. Uspoređivane su sljedeće vrste obrade: na suho, hlađenje MQCL metodom (minimalne količine maziva za hlađenje), hlađenje MQL metodom (minimalne količine maziva). Ispitivanje je provedeno u dva stadija. U prvom je određen utjecaj protoka mase aktivnog medija na oblik strugotina i $R a$ i $R q$ parametre hrapavosti obrađivane površine. U drugom je stadiju trebalo odrediti utjecaj MQL i MQCL metode na izabrane indekse postupka obrade u odnosu na obradu na suho kao funkcije promjenljive brzine rezanja. Ustanovljeno je da je, u MQL i MQC uvjetima, područje stvaranja elementarnih strugotina i onih u obliku kratkih spirala šire, u usporedbi s tokarenjem na suho. S povećanim protokom mase emulzije i ulja, stvaraju se zamršene strugotine. Hlađenjem MQL i MQC metodom dolazi do smanjenja vrijednosti izabranih parametara hrapavosti za 2 $\%$ do $42 \%$ u usporedbi s obradom na suho.

Ključne riječi: emulsijska izmaglica; $M Q C L ; M Q L$; oblik strugotine; površinska hrapavost; uljna izmaglica

\section{Introduction}

The process of cutting metals takes place in the surrounding of air or cooling and lubricating liquids (CLL) purposely supplied to the cutting area. There are many ways of delivering those substances to the cutting zone depending on the method of machining and on the material which is subjected to machining. Nowadays, due to the use of new tool materials, it is possible to apply machining technologies which do not require the application of liquids. However, in precision machining, for the sake of better geometrical state of the surface, process engineers still recommend the use of at least minimum quantity of CLL (Minimum Quantity Cooling Lubricant - MQCL or Minimum Quantity Lubricant MQL) supplied to the cutting zone by means of compressed air. The MQCL and MQL methods replace machining with the use of CLL due to its many drawbacks, because CLL is an undesired factor in the process of machining for economical, ecological, health and technological reasons [1].

The way of supplying and the quantity of CLL delivered to the cutting zone largely influence machinability of constructional materials. The application of MQCL and MQL definitely improves machinability, extends the cutting wedge life [2] and influences many other factors of the machining process - it reduces the cutting forces [3], improves heat dissipation [4] reduces the machined surface roughness $[4 \div 6]$ and influences the process of chip formation [3]. One must not forget, too, the environmental aspect. Small quantity of CLL used in the MQCL and MQL method (as little as $50 \mathrm{ml} / \mathrm{h}$ ) [1] solves the problem of CLL disposal and reduces the costs involved in the application of it [7].

Although the methods described above are promising for many machining applications $[8 \div 10]$, some basic issues related to their use, such as the selection of the conditions of creating the "active medium - air mixture" in the MQCL and MQL method have not been fully investigated [11]. Examples of experimental investigations aiming at reduction of the use of cooling lubricant substances (CLL) can be found in literature [12 $\div 14$ ], but those publications do not mention problems related to the cooling conditions and heat flow in the cutting zone. That is why one of very important parameters of selecting effective conditions of emulsion and oil mist formation and supplying is mass flow of emulsion which influences also the machined surface roughness [15].

The objective of the present paper is to determine the effectiveness of applying ecological methods of cooling as compared to dry machining, as well as to determine the influence of the emulsion mist formation conditions on the selected indices of machining.

\section{Material and methods \\ 2.1 Cutting conditions}

The tests have been performed with the use of X10CrNi18-8 stainless steel. The chemical composition, 
structure and properties can be found in Tab. 1. Cutting tests have been performed on a CU502 universal lathe with the use of a lathe tool with uncoated plate of P25 sintered carbide, with the symbol, ISO SNUN120408 fixed in holder, ISO-CSDBM 2020-M12. The wedge geometry: main cutting edge angle $\kappa_{\mathrm{r}}=70^{\circ}$, auxiliary cutting edge angle $\kappa_{\mathrm{r}}^{\prime}=20^{\circ}$, rake angle, $\gamma=-8^{\circ}$. In the MQCL method, OPORTET RG-2 emulsion concentrate has been used as the active medium. It is a universal medium applied in turning, milling and threading. It does not lose its utilization properties for a long time and does not contain such compounds as nitrates, chlorine, formaldehydes. The concentrate content in water was 4 $\%$. In the MQL method, CUTSOL oil has been used. The oil has balanced lubricating properties. It is resistant to high pressures, which is one of the main requirements imposed to processing liquids in machining processes. In accordance with the producer's recommendation, concentration of $5 \%$ has been applied.

Table 1 Chemical composition, structure and mechanical properties of X10CrNi18-8 stainless steel (according to EN 10088-1)

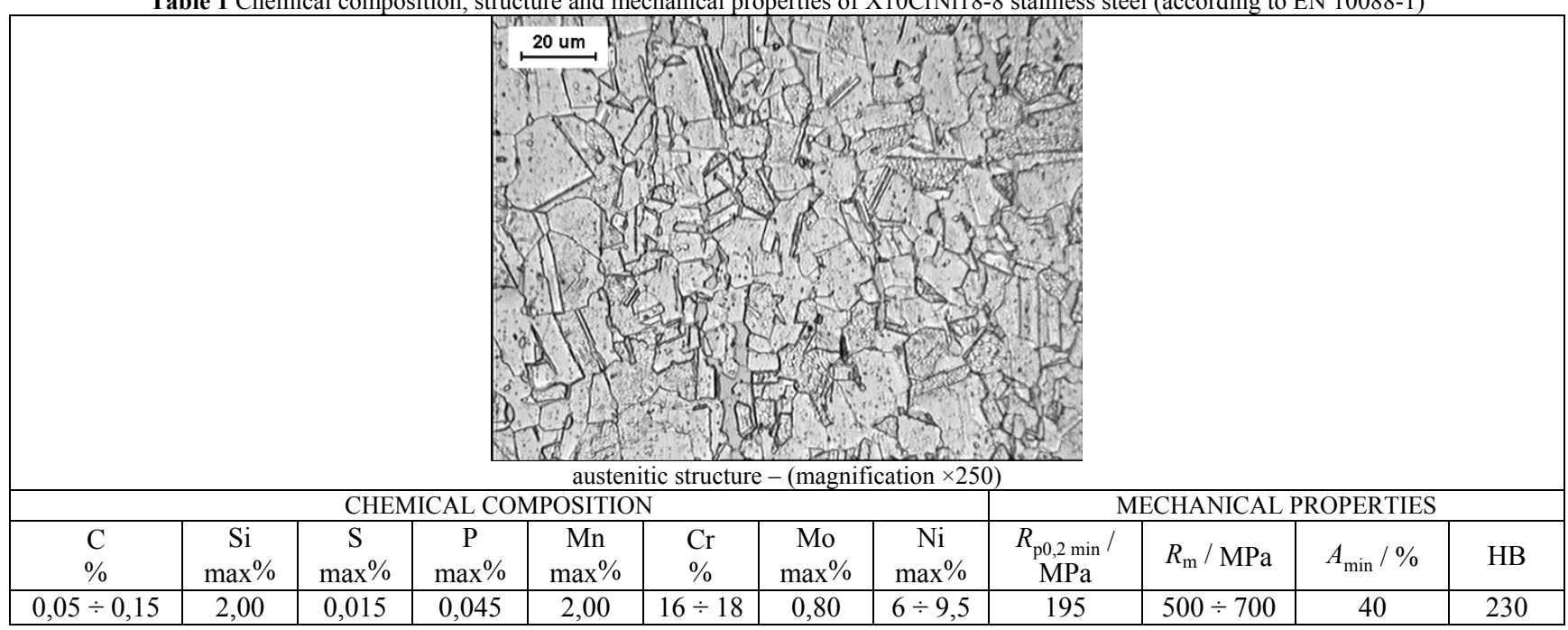

In the MQCL method, the emulsion mist has been formed with the use of Micronizer 1LN Micro Unit Wlenox Nozzle device provided with air flow and emulsion flow control nozzles. The device has been coupled to a compressor. The pressure generated by the compressor was $2 \mathrm{MPa}$.

\subsection{Experimental procedure}

The tests have been performed in the cutting speed range of $50 \div 350 \mathrm{~m} / \mathrm{min}$, feed rate range of $0,1 \div 0,5$ $\mathrm{mm} / \mathrm{rev}$, active medium flow range of $1,5 \div 3,6 \mathrm{~g} / \mathrm{min}$ and air flow range of $4,7 \div 6,9 \mathrm{~m}^{3} / \mathrm{h}$. Constant cutting depth of $1 \mathrm{~mm}$ corresponding to finish machining has been applied [7].

Roughness measurement has been performed on a TR-200 device in accordance with ISO 4287:1998 standard. The following roughness indices have been examined: arithmetical average of $R a$ profile ordinates and root mean square deviation of the assessed profile $R q$ that is functionally associated with the parameter $R a$. However, from a scientific point of view, $R q$ parameter is a better parameter, because it corresponds to the standard deviation $\sigma$ applicable in the statistics. Krolczyk et al. [16] presented influence of cutting speed on $R a$ and $R q$ parameters in dry turning of duplex stainless steel. Interesting fact is that low values of roughness parameters were shown for the lower cutting speed.

Large number of variables has necessitated the use of a contemporary method of investigation planning. For that reason, the Parameter Space Investigation method has been applied [17] which consists in locating individual examination points in multi-dimensional space so that the points of their projections on axes $X_{1}-X_{2}, X_{2}-X_{3}, \ldots$, $X_{i}-X_{j}$ are situated at equal distances between each other (Fig. 1).

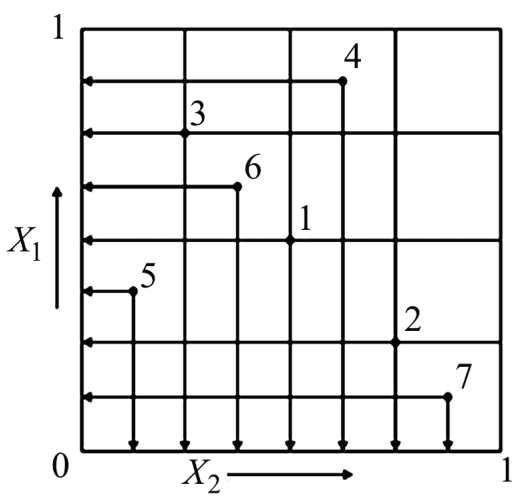

Figure 1 Design of experiment - projection of the seven examination points on the $X_{1}-X_{2}$ axes

Based on the algorithm presented in [17], a computer program has been elaborated and the coordinates of the examination points have been calculated assuming $X_{\min }=0$ and $X_{\max }=1$. Generally speaking, for the analysis of the function, $f\left(X_{i}\right)$, it is sufficient to perform examinations in seven points of the multi-dimensional space. In this case, we obtain 7 points on each of the $X_{i}$ axes because the minimum number in case of an unknown complicated function is 5 . Such number of points suffices for statistical calculation of measurement results. In Tab. 2 , one can find the coordinates of 7 examination points assuming $X_{\min }=0$ and $X_{\max }=1$. The study assumed that $X_{1}$ corresponds to the feed rate, $X_{2}$ - cutting speed, $X_{3}-$ fluid mass flow and $X_{4}$ - volumetric flow of air. 
Table 2 Coordinates of the examination points

\begin{tabular}{|c|c|c|c|c|c|c|c|}
\hline \multirow{2}{*}{ Tactor } & \multicolumn{7}{|c|}{ Point number 2 Coordinates of the examination points } \\
\cline { 2 - 8 } & 1 & 2 & 3 & 4 & 5 & 6 & 7 \\
\hline$X_{1}$ & 0,5000 & 0,2500 & 0,7500 & 0,8750 & 0,3750 & 0,6250 & 0,1250 \\
$X_{2}$ & 0,5000 & 0,7500 & 0,2500 & 0,6250 & 0,1250 & 0,3750 & 0,8750 \\
$X_{3}$ & 0,5000 & 0,2500 & 0,7500 & 0,1250 & 0,6250 & 0,3750 & 0,8750 \\
$X_{4}$ & 0,5000 & 0,7500 & 0,2500 & 0,1250 & 0,6250 & 0,8750 & 0,3750 \\
\hline
\end{tabular}

\section{Results and discussion}

\subsection{Chip shape}

In Fig. 2, one can see the changes of the chip shapes in dry turning, as well as in MQCL and MQL conditions depending on the variable cutting speed $v_{\mathrm{c}}$ and feed rate $f$.

When turning X10CrNi18-8 stainless steel, the most favourable chip shape has been observed with the application of the MQCL and MQL method. In those conditions, the range of machining parameters, at which chips in the form of short spirals or completely loose are formed, is extended (the limit is marked by the broken line in Fig. 2). Such chips do not damage the machined surface and are easy to remove from the cutting zone. On the other hand, tangled chip or one in the form of long spirals is difficult to remove and increases the machined surface roughness as a result of permanent contact with it. Fig. 3 shows the chip shape when cooling by the MQCL and MQL methods depending on the parameters of the emulsion and oil mist generation.

b)
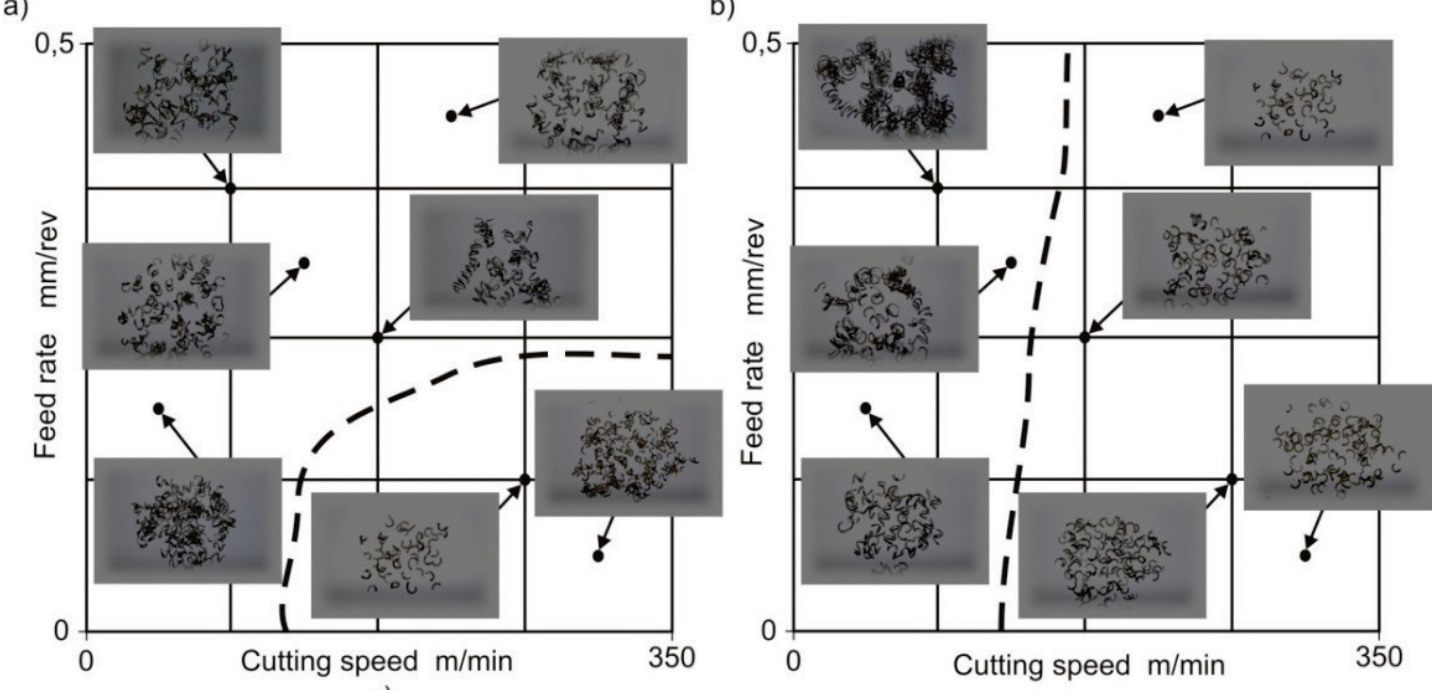

c)

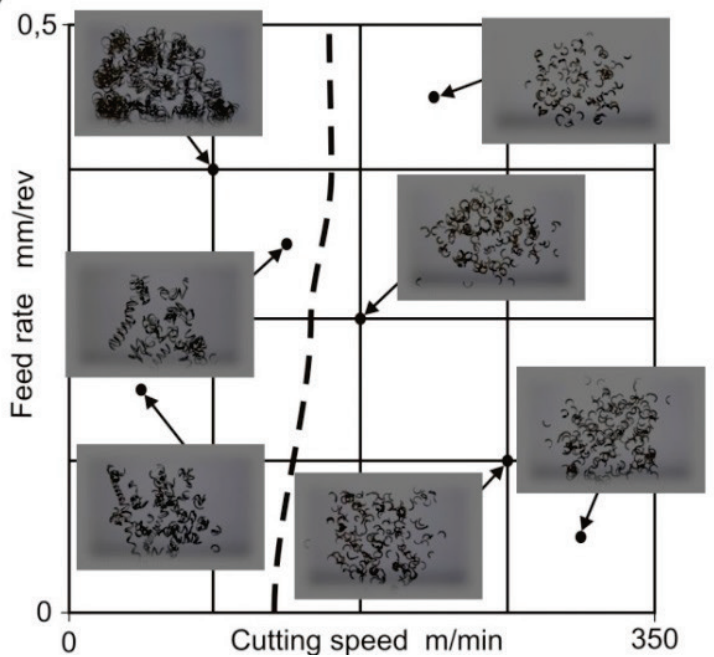

Figure 2 Changes of chip shapes when turning X10CrNi18-8 stainless steel depending on the variable cutting speed and feed rate: a) dry cutting, b) cutting in MQCL conditions, c) cutting in MQL conditions (the broken line denotes the zones of generating various chip shapes)

It has been found (Fig. 3) that tangled chips are formed only at relatively large emulsion and oil flows. In this case, the active medium interacts more effectively with the heated surfaces of the chip and tool as compared to fluid. On the one hand, the active components contained in the emulsion droplets more easily penetrate the contact surface, on the other hand, the cutting heat is dissipated from the cutting zone not only due to the phenomenon of convection but mainly due to the evaporation of micro-droplets. The process of evaporation is much more effective as compared to convection. It can be assumed that, under these conditions significant changes take place in all contact phenomena. 
a)

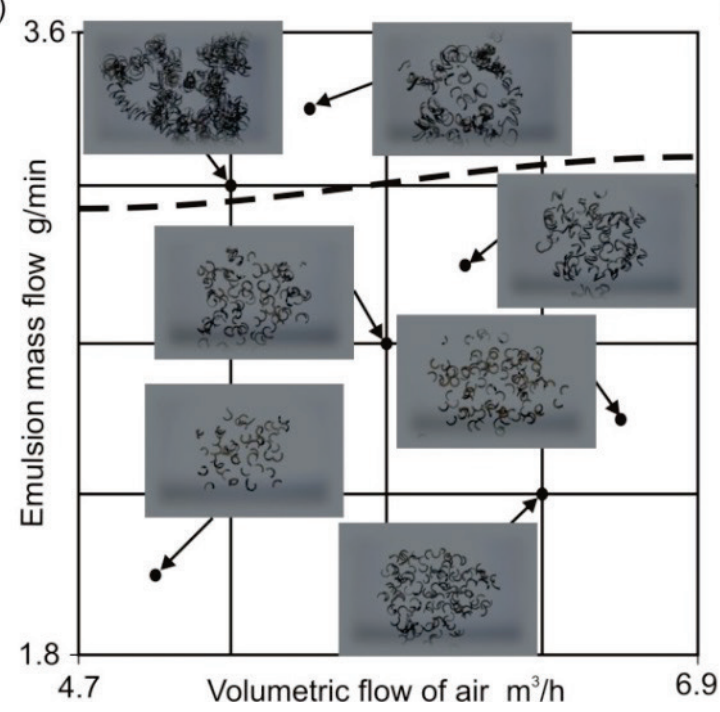

b)

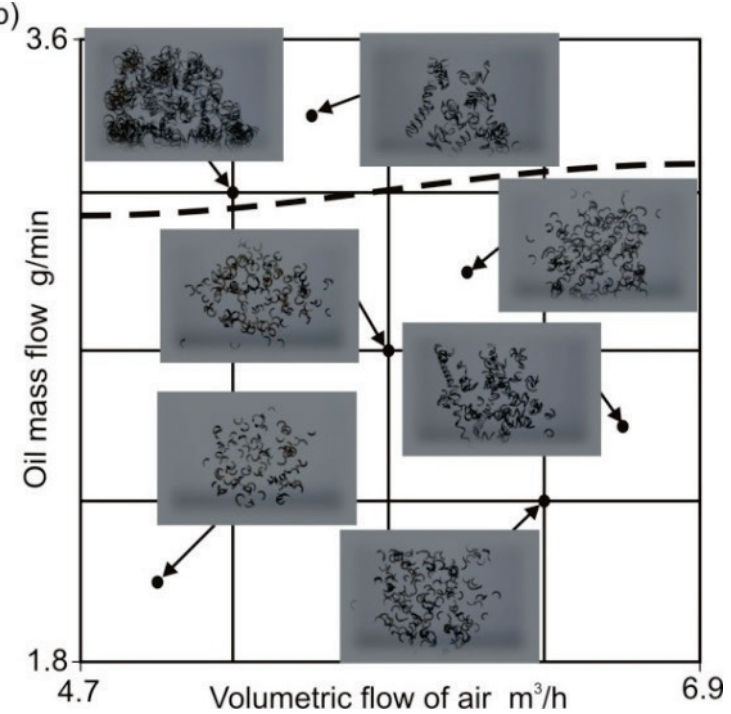

Figure 3 Changes of chip shapes when turning X10CrNi18-8 stainless steel depending on the variable mass flow of emulsion and oil and volumetric air flow: a) dry cutting, b) cutting in MQCL conditions, c) cutting in MQL conditions (the broken line denotes the zones of generating various chip shapes)

\subsection{Surface roughness of the machined material}

The measurement results of surface roughness parameters have been subjected to statistical processing with the use of Statistica computer program and then based on mathematical processing, equations of multidimensional regression have been obtained. Figs. 4 and 5 present surface roughness parameters of analysed stainless steel parts after turning process, as a function of variable cutting speed $v_{\mathrm{c}}$ : Fig. 4 - based on the regression equations; Fig. 5 - as a function of variable active medium flow.

a)

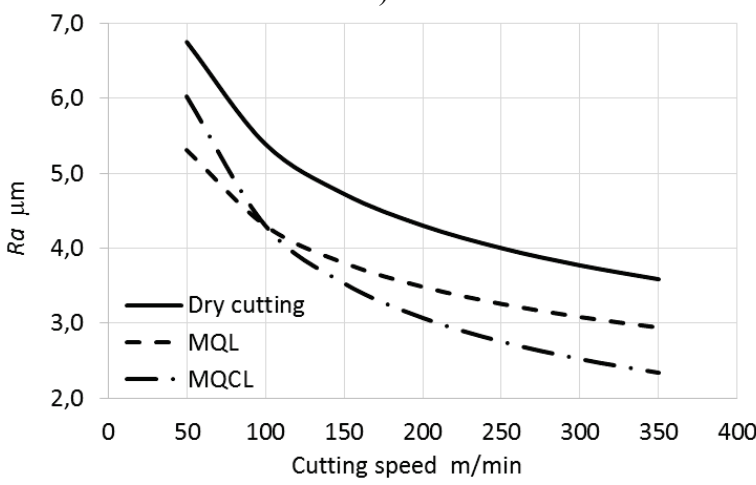

b)

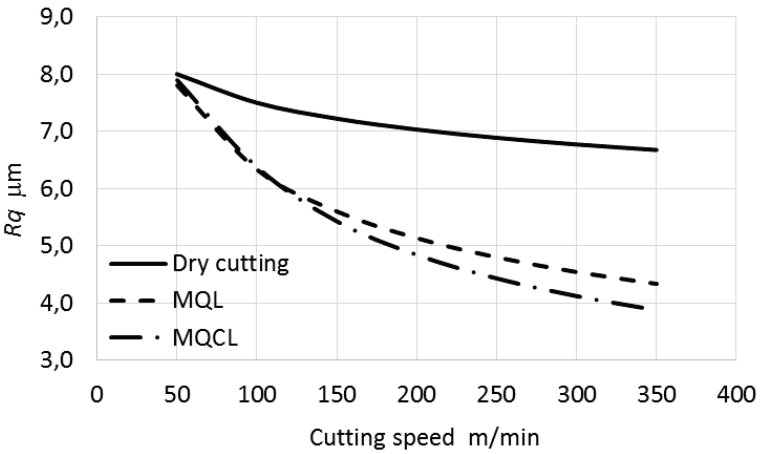

Figure 4 The influence of cutting speed $v_{\mathrm{c}}$ on the roughness parameters of X10CrNi18-8 stainless steel machined surface after turning with $f=$ $0,3 \mathrm{~mm} / \mathrm{rev}, P=5,5 \mathrm{~m}^{3} / \mathrm{h}, E=2,5 \mathrm{~g} / \mathrm{min}$ : a) parameter $R a$; b) parameter $R q$
During analysis of the data shown in Fig. 4, it has been found that the lowest values of the parameters under investigation have been obtained for cutting speed below $100 \mathrm{~m} / \mathrm{min}$ with MQL method of cooling and above that cutting speed with MQCL cooling method. Reduction of the individual surface roughness parameter values with the application of ecological cooling methods amounts from $2 \%$ to $42 \%$.

a)

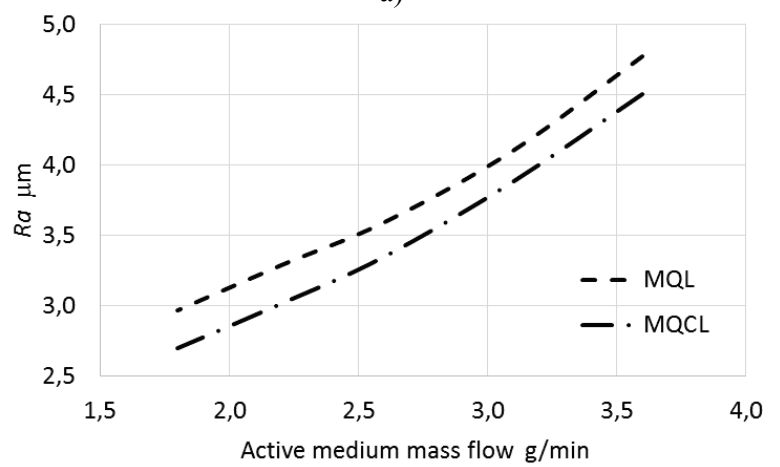

b)

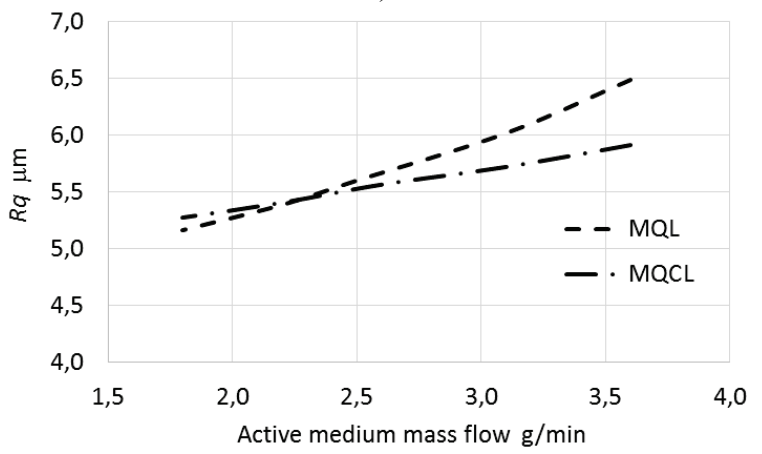

Figure 5 The influence of the active medium flow $E$, on the roughness parameters of X10CrNi18-8 stainless steel machined surface after turning with $v_{c}=150 \mathrm{~m} / \mathrm{min}, f=0,3 \mathrm{~mm} / \mathrm{rev}, P=5,5 \mathrm{~m}^{3} / \mathrm{h}$ : a) parameter $R a$; b) parameter $R q$

It has been observed (Fig. 5) that, with an increase of the active medium flow, increase of the selected roughness parameters takes place both in the MQCL and in the MQL method. For the $R a$ parameter, the lowest 
values have been obtained in the MQCL method; for the $R q$ parameter, in the MQCL method up to the value of $E$ $<2,2 \mathrm{~g} / \mathrm{min}$, in the MQL method above that value.

\section{Conclusions}

Ecological cooling methods advantageously influence selected indices of cutting as compared to dry machining. Influence of the active medium quantity on the chip shape and the machined surface roughness' has also been observed. From the present investigation, the following conclusions can be drawn:

1) It has been observed, when analysing the chip shape, that cooling by the MQCL and MQL method renders better effects as compared to dry machining. With these kinds of cooling, the range of cutting parameters in which chips in the form of short spiral sections or completely loose ones are generated. Such chips do not damage the machined surface and are easy to remove from the cutting zone.

2) Application of the MQCL and MQL method reduces the values of roughness parameters of machined surface of $\mathrm{X} 10 \mathrm{CrNi18-8}$ stainless steel as compared to dry machining.

3) Increase of the active medium mass flow results in increasing of the machined surface roughness and deterioration of effects due to the chip shape as long and tangled chips are generated. Favourable chip shapes are obtained with emulsion flow of about $E=$ $2 \mathrm{~g} / \mathrm{min}$.

\section{References}

[1] Avila, R. F.; Abrao, A. M. The effect of cutting fluids on the machining of hardened AISI 4340 steel. // Journal of Materials Processing Technology. 119, (2001), pp. 21-26. DOI: 10.1016/S0924-0136(01)00891-3

[2] Diniz, A. E.; Micaroni, R. Cutting conditions for finish turning process aiming: the use of dry cutting. // International Journal of Machine Tools and Manufacture. 42, 8(2002), pp. 899-904. DOI: 10.1016/S0890-6955(02)000287

[3] Feldshtein, E.; Maruda, R. Changes of some cutting process parameters when MQCL turning. // Advances in Manufacturing Science and Technology. 30, 3(2006), pp. 55-64.

[4] Sarikaya, M.; Güllü, A. Taguchi design and response surface methodology based analysis of machining parameters in CNC turning under MQL. // Journal of Cleaner Production. 65, (2014), pp. 604-616. DOI: 10.1016/j.jclepro.2013.08.040

[5] Sanchez, J. A.; Pombo, I.; Alberdi, R.; Izquierdo, B.; Ortega, N.; Plaza, S.; Martinez-Toledano, J. Machining evaluation of a hybrid MQL-CO2 grinding technology. // Journal of Cleaner Production. 18, (2010), pp. 1840-1849. DOI: 10.1016/j.jclepro.2010.07.002

[6] Nadolny, K.; Wojtewicz, M.; Sienicki, W.; Herman, D. An analysis of centrifugal MQL supply system potential in the internal cylindrical grinding process. // Archives of Civil and Mechanical Engineering. (2015), DOI: 10.1016/j.acme.2014.08.009

[7] Maruda, R.; Feldshtein, E. Some features of ecological finish turning of low carbon steels. // Archives of Mechanical Technology and Automation. 33, 2(2013), pp. 13-23.
[8] Rahman, M.; Kumar, A. S.; Salam, M. U. Experimental evaluation on the effect of minimal quantities of lubricant in milling. // International Journal of Machine Tools and Manufacture. 42, (2002), pp. 539-547. DOI: 10.1016/S08906955(01)00160-2

[9] Varadarajan, A. S.; Philip, P. K.; Ramamoorthy, B. Investigations on hard turning with minimal cutting fluid application (HTMF) and its comparison with dry and wet turning. // International Journal of Machine Tools and Manufacture. 42, (2002), pp. 193-200. DOI: 10.1016/S08906955(01)00119-5

[10] Sharma, V. S.; Dogra, M.; Suri, N. M. Cooling techniques for improved productivity in turning, International Journal of Machine Tools and Manufacture. 49, (2009), pp. 435453. DOI: 10.1016/j.jijmachtools.2008.12.010

[11] Park, K. H.; Olortegui-Yume, J.; Joshi, S.; Kwon, P.; Yoon, M. C.; Lee, G. B.; Park, S. B. Measurement of droplet size and volumes for minimum quantity lubrication (MQL). // International Conference on Smart Manufacturing Application, Goyang-si, Korea (South), 2008, 09-11, Apr.

[12] Pusavec, F.; Stoic, A.; Kopac, J. The role of cryogenics in machining processes. // Tehnički vjesnik-Technical Gazette. 16, 1(2009), pp. 3-10.

[13] Krolczyk, G. M.; Legutko, S. Experimental analysis by measurement of surface roughness variations in turning process of duplex stainless steel. // Metrology and Measurement Systems. XXI, 4(2014), pp. 759-770. DOI: 10.2478/mms-2014-0060

[14] Krolczyk, G. M.; Nieslony, P.; Legutko, S. Determination of tool life and research wear during duplex stainless steel turning. // Archives of Civil and Mechanical Engineering. 15, 2(2015), pp. 347-354. DOI: 10.1016/j.acme.2014.05.001

[15] Stoić, A.; Duspara, M.; Kosec, B.; Stoić, M.; Samardžić, I.The influence of mixing water and abrasives on the quality of machined surface. // Metalurgija. 53, 2(2014), pp. 239-242.

[16] Krolczyk, G.; Nieslony, P.; Legutko, S.; Hloch, S.; Samardzic, I. Investigation of selected surface integrity features of Duplex Stainless Steel (DSS) after turning. // Metalurgija. 54, 1(2015), pp. 91-94.

[17] Statnikov, R. B.; Statnikov, A. The Parameter Space Investigation Method Toolkit, Artech House, Boston/London 2011.

\section{Symbols and abbreviations}

$R a \quad-$ arithmetic average roughness $(\mu \mathrm{m})$

$R q \quad-$ root mean square deviation of the assessed profile $(\mu \mathrm{m})$

MQCL - Minimum Quantity Cooling Lubrication

MQL - Minimum Quantity Lubrication

$R_{\mathrm{m}} \quad-$ tensile strength $(\mathrm{MPa})$

$R_{\mathrm{p} 0,2 \min }$ - yield point $(\mathrm{MPa})$

$A_{\text {min }}$ - elongation (\%)

CLL - cooling and lubricating liquid

$v_{\mathrm{c}} \quad-$ cutting speed $(\mathrm{m} / \mathrm{min})$

$a_{\mathrm{p}} \quad-$ depth of cut (mm)

$f \quad-$ feed rate $(\mathrm{mm} / \mathrm{rev})$

$E \quad-$ active medium mass flow (g/min)

$P \quad-$ volumetric flow of air $\left(\mathrm{m}^{3} / \mathrm{h}\right)$

HB - Brinell hardness

PSI - Parameter Space Investigation. 


\section{Authors' addresses}

Radoslaw W. Maruda, PhD. Eng.

Faculty of Mechanical Engineering

University of Zielona Gora

4 Prof. Z. Szafrana street, 65-516 Zielona Gora, Poland

E-mail: r.maruda@ibem.uz.zgora.pl

Stanislaw Legutko, Prof. DSc. PhD. Eng., Prof.h.c.

Faculty of Mechanical Engineering and Management

Poznan University of Technology

3 Piotrowo Street, 60-965 Poznan, Poland

E-mail: stanislaw.legutko@put.poznan.pl

\section{Grzegorz, M. Krolczyk, PhD.}

Opole University of Technology

76 Prószkowska Street, 45-758 Opole, Poland

E-mail: g.krolczyk@po.opole.pl

Pero Raos, Prof. dr. sc.

J. J. Strossmayer University of Osijek

Mechanical Engineering Faculty in Slavonski Brod

Trg Ivane Brlić-Mažuranić 2

35000 Slavonski Brod, Croatia

E-mail: praos@sfsb.hr 